\title{
III. Geburtshülflich-gynäkologische Mitteilungen aus anderen Gesellschaften und Vereinen
}

I. Wissenschaftliche Vereinigung am städt. Krankenhause zu Frankfurt a. M.

(Nach Münchner med. Wochenschrift. 17. p. 937.) 2. Februar. Fischer: Über fetale

Infektionskrankheiten und fetale Endocarditis. Erscheint in der Frankfurter Zeitschrift für

Pathologie.

II. Transaction of the New York Obstetrical Society.

(Nach The Amer. Journal of Obstetrics. April.) 8. Februar. Ward berichtet über einen Fall von papillärem Ovarial-cystom. Der bei der Operation verletzte Ureter wurde in den Blasenfundus iraplantiert. Taylor: Myom, Schwangerschaft, Myomektomie. Boldt bespricht einen Fall von Pyosalpinx mit inniger Verwachsung des Wurmfort-satzes.

790

Buchanzeigen.

III. Transactions of the New York Academy of Medicine.

(N"ach The Journal of Obstetrics.) 23. Deze?nber. Brothers: 2 Fälle von Beckeneiterung.

Ladinski: Fall von Myomektomíe in der Schwangerschaft. Pool: Fall von Zwillingsschwangerschaft in einer Tube, cfr. Originalarbeiten. Stark: Fall von vorzeitig ein-getretener Menopause.

West: Repair of central laceration of levator ani and perineum.

Buchanzeigen.

Albert Blau. Über die Entstehung und Verbreitung der Tuberkulose im weib-lichenGenitaltrakte. (Aus der Kl·inik Chrobak und dem Paltaufschen Institut für allgemeine und experimentelle Pathologie in Wien). Berlin 1909, S. Karger.

Um die Art der Infektion des weiblichen Genitales mit tuberkulösem Virus und die Art des Fortschreitens des Prozesses festzustellen, hat Vert, eine Reihe von Tierversuchen ausgeführt in der Weise, dass MeeГschweinchen mit stark vii·ulentem Material geimpft wurden, entweder durch Einbringen des Virus in die unverletzte oder in die mit der Curette verletzte Scheide, durch Infektion puerperaler Tiere, sowie durch Einbringen des Infektionsstoffes in die Uterushöhle nach vorheriger Laparotomie. In einer weiteren Serie bekamen die Tiere nach Verlauf einiger Wochen eine Einspritzung von Tuberkulin Koch. Das Resultat beider Versuchsreiheii mit zusanimen 76 Tier en ergab, dass, wenn auch durch Einbringen tuberkulösen Materials in die unverletzte Scheide beim Meerschweinchen Tuberkulose erzeugt werden kann, sich das Versuchstier doch nm· im puerperalen Zustand oder nach Läsion gleich empfänglich für die Infektion zeigt, wie für diejenige durch die Haut oder des Peritoneum. Direkte Infektion der Uterushöhle nach vorheriger Laparotomie hatte ungeïähr in $50 \mathrm{pCt}$. ein positives Resultat. ,,Die deszendierende Form erklärt sich aus dem abfliessenden infizierten Sekret, für die aszendierende Form allerdings sùid die vorliegenden $\lambda$ 'ersuche 
nicht beweisend." Ein scheinbares Aszendieren erklärt sich durch gleichzeitige Infektion höher gelegener Schleimhautpartien. Blau hat dann noch 36 Fälle der Chroba $7 / 8$ schen Klinik zur Beantwortung seiner Fragen durchstudiert mit dem Ergebnis, dass miter alien diesen nicht einer sich findet, in welchem das primäre Auftreten der Tuberkulose im Genitaltrakte behauptet werden könnte, auch das Aszendieren des tuberkulösen Prozesses war in keinem Falle erweisbar.” ,,Die Erzeugung einer primären Tuberkulose des weiblichen Genitales beim Menschen scheint nicht nur günstigen Boden (Puerperium, Verletzungen), sondern auch besondere Virulenz der Infektionserreger zur Voraussetzung zu haben.” $\quad$ R. Glitsch, Stuttgart.

Anton Siízenfrey. Die Lehre von der kongenitalen Tuberkulose mit besonderer Berücksicfdigung der Placentartuberkulose. Mit 28 in den Text gedruckten Abbildungen. (Aus der k. k. deutschen geburtshülflich-gynäkologischen Universitätsklinik in Prag und der grossherzoglichen Universitätsfrauen-klinik in Giessen). Berlin 1909. S. Karger.

Verf. bespricht zunächst die Frage von der hereditären und angeborenen Disposition zur Tuberkulose, wobei er sich selbst auf den Boden der Bailsch.e $\iota$ 